\title{
InTERNATIONAL BEST PRACTICE FOR EMISSIONS AND FUEL STANDARDS: IMPLEMENTATION POSSIBILITIIES FOR ASEAN
}

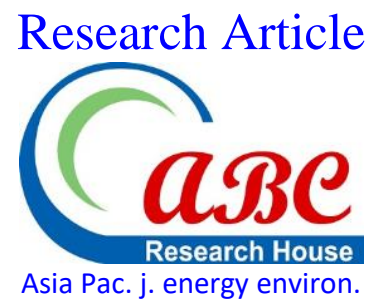

\section{Anthony David Owen*, Jacqueline Yujia Tao}

Energy Studies Institute, National University of Singapore, 29 HengMuiKeng Terrace, Block A \# 10-01, SINGAPORE

*Email for Correspondence: esiado@ nus.edu.sg

Abstract

This paper assesses the role that both vehicle emissions and fuel standards can play in moderating the projected increase in emission of pollutants from the road transport sector of Association of Southeast Asian Nations (ASEAN) member countries by adopting international best practice as it currently stands. It concludes that much could be done within ASEAN to align with international best practice in terms of vehicle emission regulations in the transport sector. In addition, exploring alternative fuels such as natural gas, ethanol, and biodiesel could also offer substantial benefits in reducing air pollutants and emissions in the short term as member countries develop their refining capabilities to produce ultra-low sulphur fuel. Until then, it is likely that vehicle emission regulations may be held back at the Euro III (3) level. Despite that limitation, improving existing motorcycle emission regulations could provide abatement possibilities, while also improving local ambient conditions. Recognizing that international best practice is limited for motorcycle emission regulations, ASEAN member countries could play a key role in drafting and possibly shaping such emission standards.

Key words

ASEAN, fuel standards, transport sector, climate change, vehicle emissions

This article is is licensed under a Creative Commons Attribution-NonCommercial 4.0 International License.

Attribution-NonCommercial (CC BY-NC) license lets others remix, tweak, and build upon work non-commercially, and although the new works must also

acknowledge \& be non-commercial.

\section{INTRODUCTION}

Despite being non-Annex I countries, some Association of Southeast Asian Nations (ASEAN) has pledged to commit to actions to mitigate climate change. For example, Indonesia has pledged to reduce emissions of greenhouse gases by $26 \%$ by 2020 , whereas Malaysia stated that it is currently on target for reducing its emissions intensity by $40 \%$ by 2020. Vietnam has pledged a reduction of emissions by $8-10 \%$ from 2010 levels, while Brunei Darussalam (hereafter Brunei) has suggested that a $63 \%$ reduction in energy consumption by 2035 is possible. Such strong commitments will require ASEAN economies to enact both extensive and intensive policies to tackle emissions from all sectors of their economies.

ASEAN economies have experienced major growth in real GDP over the past decade, averaging, as a region, $5.5 \%$ per annum from 2000 to 2012. The Organization for Economic Co-operation and Development (OECD, 2013) expects this rate of growth to continue from 2014-2018. Such growth projections give rise to concerns over greenhouse gas and other emissions of pollutants, particularly in the transport sector. Globally, direct transport emissions amounted to $7.0 \mathrm{GtCO}_{2-\mathrm{e}}$ in 2013 , or around $22 \%$ of the world's energy-related $\mathrm{CO}_{2}$ emissions. This figure is expected to climb to $12 \mathrm{GtCO}_{2-\mathrm{e}}$ by 2050under a BAU scenario (IEA, 2013). The bulk of the projected growth in transport emissions is due to rising transport demand in developing countries, such as those of ASEAN, while the trend is expected to be relatively static for developed countries. In 2011, total transport $\mathrm{CO}_{2}$ emissions in ASEAN were estimated to be around $286 \mathrm{MtCO}_{2}$, equivalent to $25 \%$ of ASEAN's total $\mathrm{CO}_{2}$ emissions from fuel combustion ${ }^{(\mathrm{IEA} / \mathrm{ERIA}, 2013)}$. The International Energy Agency (IEA) estimates that transport energy demand in ASEAN will experience an annual growth rate of $2.7 \%$, effectively doubling over the period 2011-2035. As such, policies tackling transport emissions will be critical if ASEAN countries do not wish to fall short of their climate pledges. 
This paper assesses the role that both vehicle emissions and fuel standards can play in moderating the projected increase in emissions of pollutants from the road transport sector of ASEAN member countries if current international best practice is adopted.

\section{METHODS}

\section{POLICY OPTIONS FOR DIRECT EMISSIONS REDUCTION IN THE TRANSPORT SECTOR}

Direct emissions from transport can be decomposed into three major categories: activity level, energy intensity, and fuel carbon intensity. Recognizing the financial, institutional, cultural and legal barriers that constrain the move towards "sustainable" or "green" transport, both regulatory and market-based mechanism must be adopted to incentivize the shift towards decarbonizing the transport sector. Effective mitigation policies would likely constitute a mix of policies targeting each of the factors contributing to transport emissions. Transport demand management, land-use planning, and infrastructure investment-related policies are often used to reduce the activity level whereas regulative standards are common policy instruments to regulate the energy intensity and fuel carbon intensity aspects. In various circumstances, other market-based policy instruments are also implemented alongside regulative standards to ensure maximum effectiveness of the policy.

\section{ROAD TRANSPORT EMISSIONS REGULATIONS}

Road transport, both passenger and freight, currently accounts for about $80 \%$ of all transport energy (IEA, 2012a). Emissions from road transport are often governed by two sets of regulative standards. Carbon emissions are controlled under fuel economy standards, also known as fuel efficiency standards. Fuel economy standards aim to limit $\mathrm{CO}_{2}$ emissions from transport by increasing the energy efficiency of automobiles, thereby reducing fuel consumption and associated carbon emissions. Non- $\mathrm{CO}_{2}$ emissions are regulated under vehicle emission standards, which set limits on conventional tail-pipe pollution emissions such as carbon monoxide (CO), total hydrocarbons (THC), methane $\left(\mathrm{CH}_{4}\right)$, nitrogen oxides (NOx) and particulate matter (PM).Fuel quality standards, which specify fuel quality requirements for use in engines, are often incorporated into vehicle regulation standards as several fuel properties affect the effectiveness of tailpipe emissions reduction technology. These three sets of standards work together to constrain vehicle emissions.

The United States (US) and European Union (EU) standards tend to dominate any debate on vehicle regulation. Although US standards have been adopted by Canada and Mexico, European standards have been recognized and adopted by the World Forum for Harmonization of Vehicle Regulations for the United Nations Economic Commission for Europe (UNECE), and thus have been effectively recognized as the de facto global standards. Further, many countries have either adopted the EU standards, or modified the EU standards to create their own national standards.

Any discussion on vehicle emissions regulation would have to differentiate between different classes of vehicles. The road transport vehicle fleet is broadly divided into three categories: Light Duty Vehicles (LDVs), Heavy Duty Vehicles (HDVs) and motorcycles. Though specification of categories may differ across countries, Table 1 illustrates the general consensus of vehicle classification.

Table 1: Description of Vehicle Fleet Categories

\begin{tabular}{|l|l|}
\hline Categories & Description \\
\hline LDVs & Passenger vehicles and light-duty trucks \\
\hline HDVs & Heavy duty vehicles such as trucks and buses \\
\hline Motorcycles & Mopeds, motorcycles, tricycles and three-wheelers \\
\hline
\end{tabular}

Emissions standards (both conventional and $\mathrm{CO}_{2}$ emissions) are usually prescribed and verified using driving cycles designed to reflect actual driving patterns on the road. Different testing requirements apply for LDVs and HDVs, with LDVs being limited by the pollutant mass emitted per distance travelled and HDVs being capped by the pollutant mass per unit of work done by the engine. To meet any given standard, a vehicle is tested using a standardized driving cycle for the pollutant mass limit. The results are then adjusted by a durability factor. One commonly cited weakness of the use of standardized driving cycles in estimating vehicular emissions would be the difficulty in capturing variability of other factors that affect emissions, such as driving behavior, road conditions, and weather. The US, Europe, and Japan have developed their own test procedures to capture regional variability, which creates problems in terms of international comparability of standards as different testing specifications may alter the results. It has been largely acknowledged that standardized driving tests are not directly replicable for all countries, thus it is common practice for countries without their own driving cycle to adopt a recognized framework, such as the US or European standard, and adjust for local factors to make the data regionally relevant. The UNECE has developed a worldwide harmonized test procedure for measuring the fuel efficiency and exhaust emissions of LDVs, 
the Worldwide harmonized Light vehicles Test Procedure (WLTP), which is currently undergoing a verification process. The driving cycle of the WLTP is being developed based on driving data from the European Union, the US, Japan, India and Korea. The driving cycle is likely to be composed of several distinct parts that reflect various driving patterns due to the diversity of driving patterns in these countries. Individual countries can then select the weighting they give to each part to reflect their domestic driving conditions. The WLTP is designed, therefore, to be applicable for the driving patterns of most countries around the world.

\section{VEHICLE EMISSIONS STANDARDS}

The US has historically had the world's most stringent vehicle tailpipe conventional pollutant emission standards. While the first nationwide US light duty emissions standards were implemented in 1968, the official Federal legislation that regulated conventional emissions of pollutants was only enacted in 1981 . The standards were retroactively named Tier 0 to align with a tiered system. In 1990, the Clean Air Act Amendment (CAAA) defined Tier 1 and Tier 2 of the vehicle emissions standard for light-duty vehicles. Both Tier 1 and Tier 2 standards were phased-in progressively over 3 to 5 years. The phase-in timeline was determined so as to coincide with the introduction of new car models by car manufacturers, allowing for increased flexibility and reaction time for the automobile industry.

Conventional emissions regulations for heavy duty vehicles were introduced in the US in 1974. The latest regulation, the 2007 Heavy-Duty Highway Rule, which was finalized in 2001, came into force in 2007 and was fully phased in by 2010. The 2007 standards were based on the use of high-efficiency catalytic exhaust emissions control devices that are highly vulnerable to corrosion by high sulphur content fuels. However, the sulphur content of highway diesel in the US at that time was 500ppm, 97\% higher than the required 15ppm. The US Environmental Protection Agency (EPA) established a Clean Air Highway Diesel final rule, therefore, to require local refiners to reduce sulphur content. This acted as a technology enabler for the introduction of the 2007 Heavy-Duty Highway Rule.

The development of US tailpipe emissions standards has been largely driven by the stricter California state regulations, typically with a time lag for implementation. The harmonization of both standards is often referred to as the California Effect (Vogel, 1995) as "the shift of consumer, environmental and other regulations in the direction of political jurisdictions with stricter regulatory standards". The presence of two standards in the US provides a choice for other US states to decide if they would wish to comply with the California or the Federal standard. As of 2014, 14 out of 50 US states had adopted the stricter California standards.

As of 2014, the European standard ranges from Euro 1 to 6, with Arabic numerals for LDVs and Roman numerals for HDVs. Directive 97/24/EC mandates the emissions standards for two and three-wheel vehicles in Europe, with the new Euro 4 to be implemented in 2016.

Both China and India have modelled their own vehicle emissions standards after the European standard, while also adopting the US way of maintaining two sets of standards. China's current nationwide emissions standard is the Euro IV(4) equivalent China IV for both HDVs and LDVs. China intends to implement the China 5 standard for LDVs in 2018.whilethe implementation date for HDVs has yet to be determined. India has adopted nationwide Euro III (3) equivalent Bharat III standards, while some cities have Bharat IV (4) standards in place. The stringency of standards is determined at a national level for the Chinese system. After that states may voluntarily implement ahead of the implementation timeline so as to pursue more aggressive transport policies. In the case of India, the Auto Fuel Policy of 2003 sets separate standards for some metropolitan cities that are distinct from the nationwide standard. Although there is a progressive inclusion of more cities into the list for stricter standards, there seems to be a lack of a long-term political signal. As such, inter-state emissions leakage is common, in that many vehicles that operate within cities with more stringent emissions have been bought and registered in other cities that require lower standards; thereby potentially compromising the effectiveness of the policy.

\section{FUEL QUALITY STANDARDS}

Fuel quality is critical for the move towards higher vehicle emissions standards as fuel properties have a major impact on overall vehicle emissions. Sulphur naturally occurs in crude oil. As previously noted in the case of the implementation of the 2007 Heavy-Duty Highway Rule, low sulphur fuel is a technological enabler for efficient emission control in vehicles. Reduced sulphur content in fuels will improve the emissions reduction capabilities of all catalyst-equipped road vehicles. In addition to sulphur content, other fuel properties also contribute to reductions in vehicle emissions. Table 2 summarizes some key parameters that contribute directly to vehicle emissions. 
Table 2: Fuel Properties and Effect on Emissions

\begin{tabular}{|l|l|}
\hline Diesel \\
\hline Cetane & Increased cetane content reduces exhaust emissions such as NOx, HC, CO \\
\hline Sulphur & $\begin{array}{l}\text { Contributes directly to reduced PM emissions } \\
\text { Reduce efficiency of, or render useless, exhaust after-treatment technology }\end{array}$ \\
\hline Aromatics & Increased aromatics content increased exhaust emissions such as NOX, PM, PAH \\
\hline Gasoline & \multicolumn{2}{|l|}{} \\
\hline Octane & Increased octane content increase fuel efficiency possibilities and reduced CO2 emissions \\
\hline Sulphur & $\begin{array}{l}\text { Contributes directly to reduced PM emissions } \\
\text { Reduce efficiency of, or render useless, exhaust after-treatment technology }\end{array}$ \\
\hline Lead & Reduce efficiency of, or render useless, exhaust after-treatment technology \\
\hline Manganese & Reduce efficiency of, or render useless, exhaust after-treatment technology \\
\hline Aromatics & Increased aromatics content increased exhaust emissions such as NOX, PM, PAH \\
\hline
\end{tabular}

Source: www.acea.be/uploads/publications/Worldwide_Fuel_Charter_5ed_2013.pdf

Sulphur content is a key limiting factor in rolling out more stringent vehicle emissions standards in developing countries. Developing countries such as Brazil, China, India and South Africa typically started with fuel that contains up to 3000 sulphur parts per million in year 2005. However, drastically decreasing sulphur content often puts pressure on national refining capabilities, or increased demand for better quality, and often pricier, fuel imports. Despite that, China has successfully reformed its domestic oil and gas refining sector to provide low-sulphur fuel (50ppm), thus enabling it to roll out one of the most stringent vehicle emission standards in the developing world.

\section{FUEL ECONOMY STANDARDS}

According to industry estimates, only $12.6 \%$ of original energy is utilized for vehicle movement (IMF, 2014). Currently, a variety of different technologies exist to increase the fuel economy of new vehicles by $50 \%$ by 2030 in a cost effective manner. To date, fuel economy standards have been implemented for LDVs in most OECD countries and some developing countries, covering 70\% of global transport emissions (IEA, 2012a). Fuel economy of on-road vehicles is a measure of the efficiency of the energy conversion from the fuel in use to mechanical energy at the wheel. It is represented as a ratio of the quantity of energy needed to cover a certain distance, although sometimes emissions equivalents, such as $\mathrm{CO}_{2}$ or $\mathrm{CO}_{2}$ e, are also used. Fuel economy standards typically set maximum limits of energy use or emissions per kilometre of driving. Such standards can be levied on either individual models or as a corporate fleet average. The corporate fleet average structure offers more flexibility for car manufacturers and allows for a variety of vehicle types on the market. Car manufacturers are permitted to comply with the existing regulation either by focusing on a range of highly energy efficient cars or by increasing the fuel economy of the entire fleet marginally. However, the environmental benefits of such a structure may be compromised as highly non-efficient models may dominate the vehicle population. Adopting an individual model fuel economy standard may be more environmentally effective, but it would be expected to incur more administrative and implementation costs.

The US CAFE (corporate average fuel economy) standards are one of the most recognized fuel economy standards globally, having been in place since the 1970s. Traditionally, the US standard has employed a fuel economy metric. However, following a 2007 Supreme Court ruling that $\mathrm{CO}_{2}$ is considered a pollutant, the latest CAFE regulations has been extended to include greenhouse gas (GHG) emissions, including carbon dioxide $\left(\mathrm{CO}_{2}\right)$, methane $\left(\mathrm{CH}_{4}\right)$, nitrous oxide $\left(\mathrm{N}_{2} \mathrm{O}\right)$, and hydro fluorocarbons (HFCs). The existing 2012-2016 CAFE/GHG standards mandate that the average light duty vehicle GHG emission rate is to be reduced by $4.2 \%$ per model per year on average, and by a $3.7 \%$ increase per model per year in miles-per-gallon fuel economy. Financial penalties are imposed should CAFE regulations be violated. The US has also introduced a Gas Guzzler Tax, which is levied on individual passenger car models that cannot comply with the 22.5 miles per US gallon (10.5 litres $/ 100 \mathrm{~km}$ ) minimum to ensure environmental effectiveness of the standard.

China imposed fuel economy standards on individual models during Phase I (2005-2006) and II (2008-2009). The Chinese system uses a weight-based standards system whereby vehicle models are classified by their curb mass and have to comply with their respective fuel consumption regulations prior to entering the market. The relative success of the standard can be illustrated by its resultant overall reduction in fleet fuel consumption by approximately 10\%between 2002 and2008. While maintaining individual vehicle standards, China has also built more flexibility into the system by including a corporate fleet average metric for Phase III (2012-2015).The corporate fleet average required is slightly stricter than the summation of per-vehicle limit values, thus requiring car manufacturers to produce better performing models than mandated minimums. Flexibility mechanisms are also built into the corporate average fuel consumption (CAFC) structure, such as disproportionately assigning heavier weights for electric cars and car models with fuel economies meeting certain thresholds, and the relaxation of requirements in the following year should a car 
manufacturer be able to have a CAFC lower than the limit. The first flexibility mechanism incentivizes the production of green vehicles, such as fuel cell, electric and plug-in vehicles, while the second encourages technological innovation. Phase (IV) of China's program is expected to retain the twin structure of the existing program.

The European Union started implementing voluntary fuel economy targets in 1995, and in 1998 it signed voluntary agreements with the European Car Manufacturers Association (ACEA), Japan Automobile Manufacturers Association (JAMA), and Korean Automobile Manufacturers Association (KAMA) to keep to a CO2 emissions target of $140 \mathrm{~g} / \mathrm{km}$ by 2008 for ACEA and 2009 for JAMA and KAMA. Mandatory standards were introduced in 2009 for passenger cars and 2011 for light commercial vehicles, requiring the corporate fleet average CO2 emissions of all new vehicles to be reduced to $130 \mathrm{~g} / \mathrm{km}$ by 2015 for passenger cars and $175 \mathrm{~g} / \mathrm{km}$ for light commercial vehicles. More stringent long-term targets were also established at the outset. Various flexibility mechanisms are available for car manufacturers such as higher weights for green cars, exemption for low-volume manufacturers, use of eco-innovation credits and pooling mechanisms. If a car manufacturer is unable to comply with the standards despite these mechanisms, it will incur financial penalties.

The Japanese fuel economy standard is part of Japan's broad "Top Runner" system for energy, which adopts a benchmarking approach. The fuel economy regulation uses a weighted corporate average method and sets targets based on the best performance in the industry. In this continuous program, the best performing car manufacturer is first identified after which other car manufacturers are expected to reach the performance level of the best performing industry player before a target deadline. Penalties for non-compliance are implemented through a "name and shame" approach.

Heavy-duty vehicles (HDVs) accounted for $36 \%$ of oil consumption and GHG emissions from the transportation sector in 2010 (IEA, 2012b). Despite the eagerness of many countries to implement a standard, progress is slow as even the early movers such as the US and Japan have only recently started their pilot programs. The varied usage patterns and vehicle dimensions of the HDV fleet have made HDV regulations more challenging for regulators.

Japan introduced its first fuel economy standards for new heavy-duty diesel vehicles in 2002, however the deadline for compliance was delayed until 2015 to allow car manufacturers to comply with the 2009 HDV emissions standards which were viewed to be of higher priority.

China is the only country with an existing fuel economy standard for motorcycles (two and three wheelers). Standards for motorcycles and mopeds were adopted in 2008, with effect from 2009. China's standard governing two and three wheelers is a fuel consumption based standard, whereby maximum fuel consumption limits are set on a metric of one litre per 100 kilometres travelled. Currently all two and three wheelers with engines greater than 1250cc are covered under the scheme. Since 2010, the EU has required motorcycle manufacturers to report emissions, indicating possible regulatory intentions. However, to date, no specific targets have been set.

\section{Supplementary Policies}

As an initial step towards mandating fuel economy standards, many countries have adopted supporting policies such as fuel economy labelling. The intention is that the provision of high-quality information on vehicle fuel economy to prospective vehicle purchasers should serve to educate the public on fuel efficiency and induce changes in buyer behavior. Such practices could also help to pressurize car manufacturers and incentivize the move towards more energy efficient cars. Fuel economy labelling programs can be either mandatory or voluntary. The European Union has required passenger car (LDV) $\mathrm{CO}_{2}$ emissions labelling since 2001 in all member states. However, member states are free to choose the design of the label, leading to a variety of different labelling systems across Europe, with differing metrics and standards. Although many European countries have selected the graphical rating format, representation differences make comparison across different countries difficult. Given that the European car market is generally viewed as a single market, the use of different labelling systems hinders effective market integration. Unlike fuel economy standards, which often only target new vehicles, labelling programs often extend their reach to used car sales, given that it is widely recognized that it is impractical and costly to improve efficiency of the existing vehicle stock. Various developing countries such as Brazil, Chile, Singapore, and Thailand have also adopted fuel economy labelling programs.

The development of HDV fuel economy labelling, facing the same challenges as fuel economy standards, is still lagging internationally. Recent developments have largely adopted an accreditation approach whereby vehicles meeting certain requirements are given accreditation. Examples of these include the labelling of HDVs already meeting the 2015 legal requirements which signifies that they are eligible for fiscal incentives in Japan and the US SmartWay Technology programme that awards the SmartWay label to HDVs meeting its requirements.

Fiscal measures, such as vehicle taxes, tax incentives, and fuel taxes, are also used to increase deployment of more energy efficient vehicles. Vehicle taxes instituted at the point of purchase may be a suitable incentive for the purchase of more fuelefficient cars. Various countries have implemented creative tax regimes that align the vehicle tax structure to favor fuelefficient cars. For example, vehicle taxes in many European countries are pegged to the emissions of the vehicle, while in 
Japan vehicle taxes are based on the difference between the vehicle's fuel economy and pre-determined target values. In developing countries such as China and India, the vehicle tax structure is less sophisticated, with tax rates linked to engine size. In addition to promoting fuel efficiency, many countries also provide financial incentives, or rebates, for the purchase of "green" vehicles, such as hybrid and electric cars. Fuel tax is also an alternative policy instrument. It is often viewed as a tool to manage consumer driving behavior after the vehicle purchase. Fuel consumption spending is one of the major spending streams for a car, and thus imposition of fuel taxes may serve to reduce vehicle use and hence fuel consumption. However, fuel taxes are often highly politically sensitive, particularly from a social equity perspective.

High-quality fuel economy measurement information and testing data are required to ensure the effectiveness of fuel economy policy instruments. Currently, the four largest automobile markets, the US, the EU, China, and Japan, each have different test-cycle approaches. This highlights an underlying issue of lack of comparability between markets, which may pose challenges in the future when attempting to establish a global common standard for fuel economy.

\section{RESULTS}

\section{ASEAN}

Table 3 gives a comparison of the socio-economic conditions of ASEAN member states.

Table 3: Comparison of ASEANsocioeconomic indicators (2013)

\begin{tabular}{|l|l|l|l|l|}
\hline $\begin{array}{l}\text { ASEAN Member } \\
\text { State }\end{array}$ & $\begin{array}{l}\text { GDP }(\$ U S \\
\text { billions; PPP) }\end{array}$ & $\begin{array}{l}\text { Population } \\
\text { (millions) }\end{array}$ & $\begin{array}{l}\text { GDP/capita } \\
(\$ \mathrm{US} ; \text { PPP })\end{array}$ & $\begin{array}{l}\mathrm{CO}_{2} \text { (2010) emissions } \\
\text { (tonnes/capita) }\end{array}$ \\
\hline Brunei & 29.99 & 0.41 & 73,823 & 22.9 \\
\hline Cambodia & 46.11 & 15.09 & 3,056 & 0.3 \\
\hline Indonesia & 2388.95 & 247.95 & 9,635 & 1.8 \\
\hline Laos & 31.59 & 6.77 & 4,666 & 0.3 \\
\hline Malaysia & 693.59 & 29.95 & 23,160 & 7.7 \\
\hline Myanmar & 221.48 & 50.98 & 4,345 & 0.2 \\
\hline Philippines & 643.08 & 97.48 & 6,597 & 0.9 \\
\hline Singapore & 425.25 & 5.40 & 78,762 & 2.7 \\
\hline Thailand & 964.50 & 68.23 & 14,136 & 4.4 \\
\hline Vietnam & 474.95 & 89.69 & 5,295 & 1.7 \\
\hline
\end{tabular}

Sources: IMF (2014)

In addition to high projected growth rates, motorization rates are also expected to grow significantly over the next couple of decades. Figure 1 gives estimates of vehicle growth for six ASEAN countries to 2035. The projected strong growth rates are predominantly for motorcycles, personal cars and light-commercial vehicles arising from the assumed linear relationship between economic growth and the demand for transport. This rapid growth in vehicle demand would then translate into an increase in transport externalities that would need to be managed effectively and efficiently.

Figure 1: Growth of Motor Vehicles per Mode for Selected ASEAN Countries Source: [16]

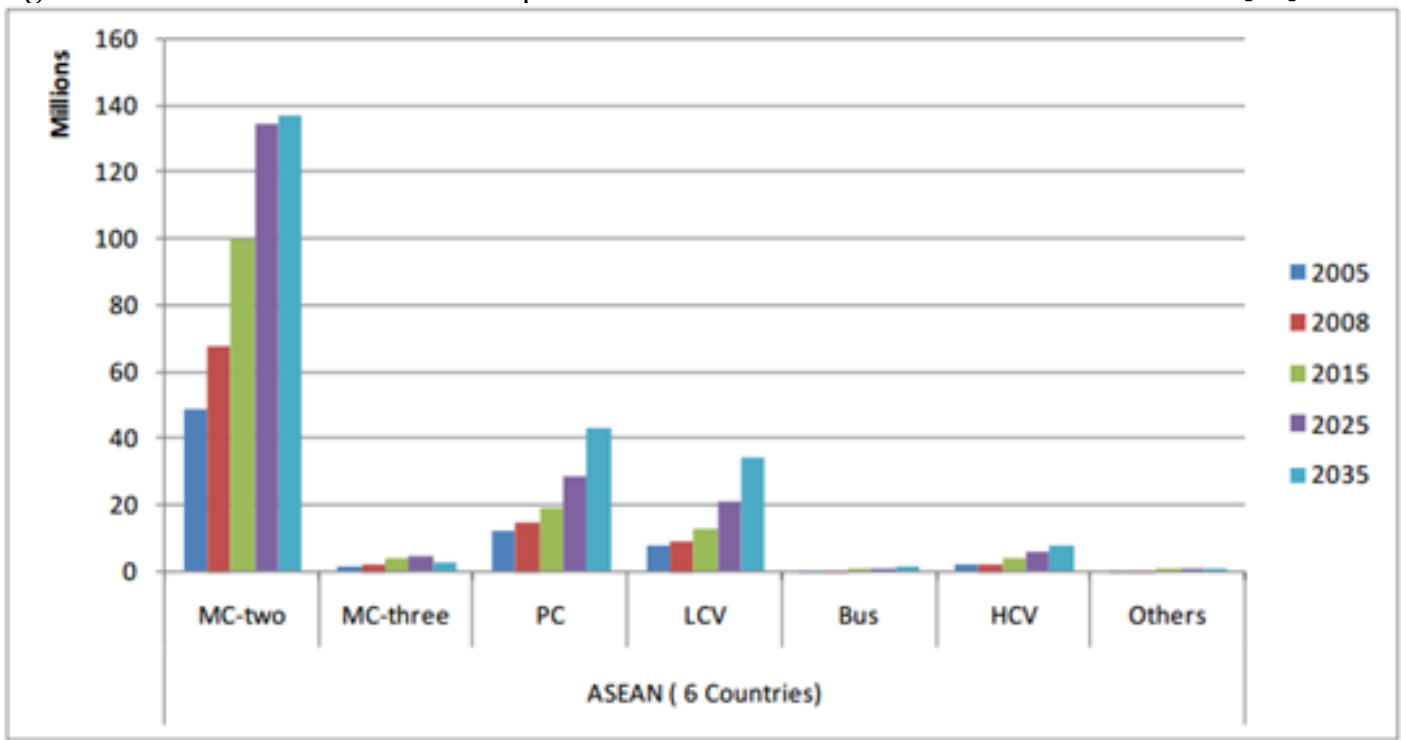

Source: http:/ / data.worldbank.org/indicator 


\section{CO-BENEFITS OF TRANSPORT EMISSIONS POLICY IN ASEAN}

The IEA estimates that oil-based fossil fuels will continue to dominate the ASEAN transport sector, amounting to $90 \%$ of total demand in 2035 (IEA/ERIA, 2013). Despite being relatively well endowed with oil reserves, as a region ASEAN has been a net importer of oil since 2004. With ASEAN oil consumption consistently outpacing its oil production, unrestrained increases in oil consumption could lead to both energy security and foreign exchange concerns for many ASEAN member countries.

Local air pollution, especially in key metropolitan cities, is a key policy concern for ASEAN countries. Various local pollutants, such as small particulate matter (PM10 and PM2.5) and other tail-pipe pollutants such as carbon monoxide $(\mathrm{CO})$, oxides of nitrogen $(\mathrm{NOx})$, sulphur dioxide $\left(\mathrm{SO}_{2}\right)$, ground-level ozone, and benzene can be actively limited and controlled with transport emissions reduction policies such as vehicle emissions standards.

Improvement in ambient air quality and reduction in local air pollution could also translate into positive health impacts, such as reduced risks of cardiovascular and respiratory disease, as well as fewer premature deaths. It is estimated that in $2010,57.8 \%$ of the residents of Jakarta experienced air-pollution related diseases such as asthma, broncho-pneumonia, and chronic obstructive pulmonary disease. The associated social cost was estimated to be around 38.5 trillion Indonesian rupiahs (US\$3.0 billion), a figure that not include any estimate of the reduction in the productive capacity of the workforce (Safrudin et al., 2013). Thus, it is expected that transport emissions management policies could bring significant health benefits while also contributing towards the containment of the socio-economic costs of local air pollution.

Significant economic benefits could also be achieved by harmonizing regional vehicle emissions standards with mutual recognition of certification. The year 2015 marks the beginning of a move by ASEAN member countries to create a single market within ASEAN, effectively an Economic Community. Steps towards creating a single automotive market would be highly beneficial for domestic car manufacturers in some member countries, particularly Indonesia, Thailand and Malaysia, who will be exposed to larger markets with the harmonization of vehicle regulations and abolition of regional tariffs.

The implementation of policies targeting transport emissions would not only address the imminent issue of climate change mitigation, but also contribute to various socio-economic policy goals. Recognizing the multiple benefits of transport emissions mitigation, many ASEAN member countries have, or are moving towards, implementing policies targeting that specific goal.

\section{OVERVIEW OF ASEAN VEHICLE EMISSIONS REGULATIVE STANDARDS}

Most ASEAN countries have adopted the European system for their vehicle emission standards. However, stringency of emissions standards is disparate amongst member countries (Table 4). Singapore and Thailand are seen to be forerunners in this context, with earlier implementation timelines and tighter standards than other ASEAN member countries. Most ASEAN countries have also stated their intentions to leapfrog to more stringent standards from 2015-2016. Singapore even proposed to move into Euro 6 in 2017, which signals a strong political commitment to limiting its transport emissions. At the other end of the spectrum, countries such as Laos, Cambodia and Myanmar currently have no emissions standards in place.

Table 4: Comparison of LDV Vehicle Emissions Standard in ASEAN countries

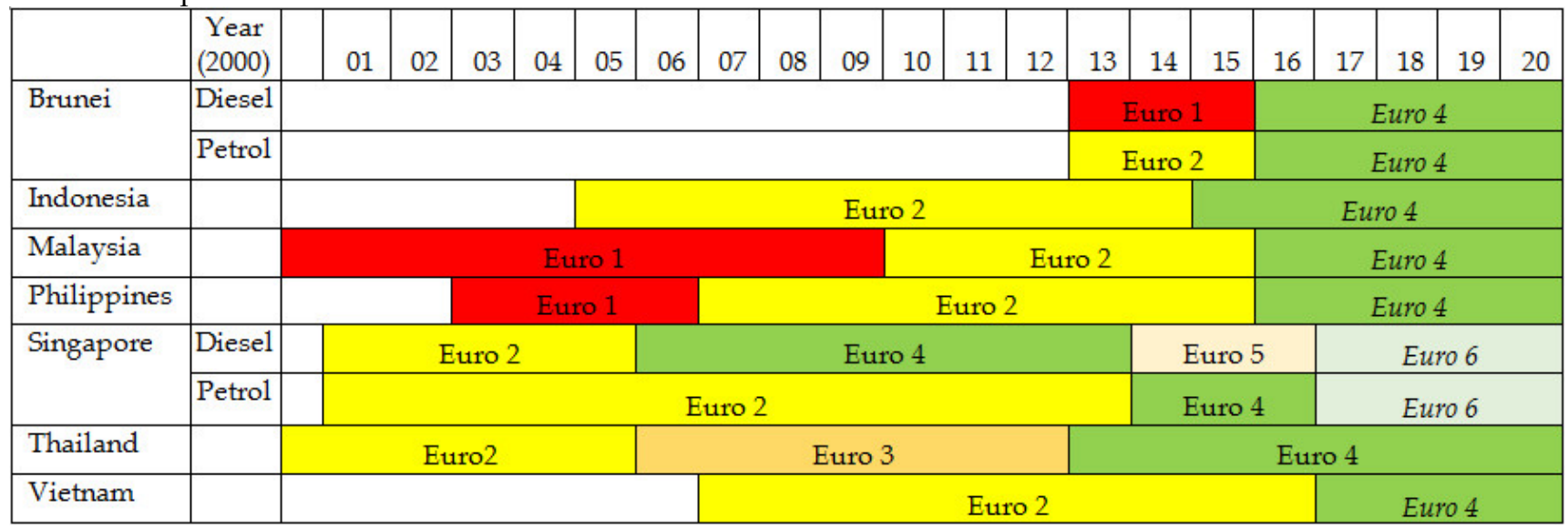

Sources: Silitonga et al., 2012 
Compared to LDVs, ASEAN countries are lagging behind in introducing vehicle emissions standards for HDVs (Table 5), although heavy-duty vehicles accounted for more than 80 percent of fine particulate (PM2.5) and nitrogen oxide (NOx) emissions from on-road vehicles in the region in 2010.

Table 5: Comparison of HDV Vehicle Emissions Standard in ASEAN countries

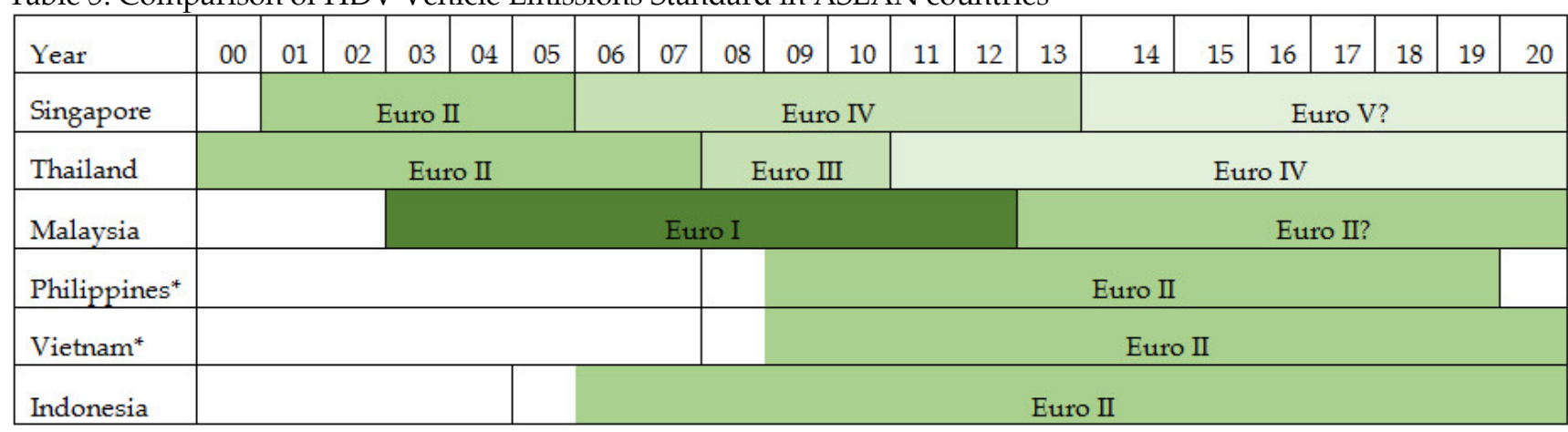

Sources: Silitonga et al., 2012

Motorized motorcycles are projected to see the highest growth rates in the transport sector. However, existing regulations on vehicle emissions standards in this category are relatively weak. With the exception of Singapore, Thailand, and Vietnam, none of the other ASEAN countries have actively tackled emissions from motorcycles. Of particular note is the fact that Vietnam has one of the strictest vehicle emissions standards for motorcycles in ASEAN, which may stem from the fact that Vietnam has a transportation fleet dominated by this mode of transport.

One likely reason for the delays of major advancements in vehicle emissions standards in ASEAN may be the lack of, or inaccessibility to, low or ultra-low sulphur fuels. Apart from Singapore and Thailand, no ASEAN country has fuel grades above Euro 3, which limits vehicle emissions standards therefore to Euro 3 and below. It follows that before any significant leapfrogging can be made in terms of vehicle emissions standards, fuel quality has to be improved. Many ASEAN countries have recognized the need to increase fuel quality and thus have set aside clear goals to increase accessibility to low-sulphur fuels by 2016. While this trend is very positive, it should be noted that increasing the demand for high-quality fuel may put supply pressure on local refining capabilities. Should local refining facilities not be able to meet such stringent requirements on a commercial scale, the import of high-quality fuels would then be required as a policy enabler. In turn, the import of high-quality fuel could raise questions with regards to foreign reserves and may also raise political and energy security concerns. To compound the complexity of the issue further, fuel subsidies, which are prevalent in many ASEAN member countries, may also have to increase to offset the impact of more expensive imported fuels. Over recent years, there has been increased political will within the region to reduce these subsidies. The progressive reduction of fuel subsidies could also contribute to a reduction in the use of automobiles due to higher fuel costs, which would clearly translate into a positive outcome in terms of reduced emissions of pollutants.

With regards to fuel economy standards, as of 2013 no ASEAN country has institutionalized mandatory standards on fuel efficiency. However, there are many tax incentives in these countries that are positioned to increase the use of greener cars. Policies targeting both the demand and supply side are employed. In countries where a domestic automanufacturing market is present, tax incentives to promote the design and production of cars that produce lower emissions have been introduced. On the supply side, various tax rebates and information dissemination policies have been explored, while fuel economy labelling has been adopted in the more advanced countries such as Thailand and Singapore. Tax rebates and incentives have also been adopted to provide incentives for the purchase of low emissions emitting automobiles.

\section{IMPLEMENTATION POSSIBILITIES IN ASEAN}

The speed of development of transport emissions reduction policies isvaried and diverse in ASEAN, partially due to the differing stages of economic development of member countries. However, the political will and determination to tackle transport emissions appears to be present in all member states, which is a positive sign should ASEAN member states move towards to international best practice as a region.

ASEAN presents a unique opportunity for possible replication of the "California Effect", whereby one country may adopt a stricter environmental standard than the others, which of manufacturing necessity has to be extended to all member states in the longer term. A variety of different approaches could be adopted to capitalize on the "California Effect". Learning from the Chinese experience, an overarching ASEAN commitment could be established to meet 
international best practice by a stated deadline. Individual countries with more ambitious targets could voluntarily accelerate the process. This would align with the ASEAN commitment to integrating energy markets from 2015, while also ensuring long-term harmonization objectives of the AEC. On the other hand, the US approach, whereby national policy is driven by the most stringent state-level policy, may also be explored. Having two sets of complementary policies available provides member countries with the choice to implement less stringent policies as a pre-cursor and to facilitate a smoother transition to gradual tightening of regulations.

Since the tightening of vehicle emissions reduction in ASEAN is mainly restricted by limited access to ultra-low or low sulphur fuel, developing strong standards for motorcycle emissions reduction may be a policy priority in the short term. While international best practice does not seem to place a priority on motorcycles, due to relatively low ridership, motorcycles are expected to experience the highest growth rate in the coming decades for the ASEAN road transport sector. The current state of motorcycle emissions regulations is woeful and would have to increase in stringency in order to address local air pollution issues in the region.

Promotion of alternative fuels for transport, especially biodiesel, may be a possible policy substitute for the use of ultra-low sulphur fuel in ASEAN in the medium term. Fuel economy labelling could be used as a key policy measure to influence consumer behavior and, with the AEC set to commence in 2015, there is an ideal opportunity to ensure harmonization of fuel economy labels within the region to avoid future issues of compatibility.

\section{Discussion AND Conclusions}

This review indicates that much could be done within ASEAN to align with international best practice in terms of vehicle emission regulations in the road transport sector. Exploring alternative fuels such as natural gas, ethanol, and biodiesel could also offer substantial benefits in reducing air pollutants and emissions for ASEAN member countries in the short to medium term as member states develop their refining capabilities to produce ultra-low sulphur fuel. Until then, it is likely that vehicle emission regulations may be held back at the Euro III (3) level. Despite that limitation, improving existing motorcycle emission regulations could provide abatement possibilities, while also improving local ambient conditions. Recognizing that international best practice is limited for motorcycle emission regulations, ASEAN member countries could play a key role in drafting and possibly shaping such emission standards. Although vehicle emission regulative standards could be a cost-effective and efficient policy tool for limiting pollutants, the integration of such policies into national transport policies would ensure maximum efficacy of the mechanism. ASEAN member countries can learn from Indonesia's example of implementing transport emission reduction policies under the umbrella of its National Action Plan for Greenhouse Gas Emissions Reduction (GAN-GRK), which then ensures coordinated policy action. Ultimately, the establishment of a common framework for emission standards in ASEAN has to take into account the heterogeneity of the region. This would require the cooperation of all ASEAN member countries.

\section{References}

International Energy Agency (IEA). CO2 Emissions from Fuel Combustion Highlights. Paris: OECD/IEA; 2013.

International Energy Agency (IEA). Policy Pathways: Improving the Fuel Economy of Road Vehicles, a policy package. Paris: OECD/IEA; 2012b.

International Energy Agency (IEA). Technology Roadmap: Fuel Economy of Road Vehicles. Paris: OECD/IEA; 2012a.

International Energy Agency and Economic Research Institute for ASEAN and East Asia (IEA/ERIA).South East Asia Energy Outlook. Paris: OECD/IEA; 2013.

International Monetary Fund (IMF). World Economic Outlook Database, October 2014, www.imf.org/external/pubs/ft/weo/2014/02/weodata/index.aspx.

Organisation for Economic Co-operation and Development (OECD) Development Centre.Economic Outlook for Southeast Asia, China and India 2014: Beyond the Middle-Income Trap. Paris: OECD; 2013.

Safrudin, A., Palguna, A., Adrison, V., Khoirunurrofik, Haryanto, B., Krisnawati, L., Zakaria, M., Hamonangan, E., Nurafiatin, L., Suhud, M., Reksowardojo, A.,and Huda, A. (2013). Cost-Benefit Analysis for Fuel Quality and Fuel Economy Initiative in Indonesia. Jakarta, Indonesia: Ministry of Environment, Assistant Deputy for Mobile Source Emission.

Silitonga, A. S., A. E. Atabani, and T. M. I. Mahlia. "Review on fuel economy standard and label for vehicle in selected ASEAN countries." Renewable and Sustainable Energy Reviews 16.3 (2012): 1683-1695

Vogel, D. Trading Up: Consumer and Environmental Regulation in a Global Economy. Cambridge, MA: Harvard University Press; 1995. 
